\title{
Integration of basic electromagnetism and engineering technology
}

\section{Bentz, Sigurd}

\section{Published in:}

Proceedings of Frontiers in Education Conference

Link to article, DOI:

10.1109/FIE.1995.483178

Publication date:

1995

Document Version

Publisher's PDF, also known as Version of record

Link back to DTU Orbit

Citation (APA):

Bentz, S. (1995). Integration of basic electromagnetism and engineering technology. In Proceedings of Frontiers in Education Conference (Vol. Volume 2). IEEE. https://doi.org/10.1109/FIE.1995.483178

\section{General rights}

Copyright and moral rights for the publications made accessible in the public portal are retained by the authors and/or other copyright owners and it is a condition of accessing publications that users recognise and abide by the legal requirements associated with these rights.

- Users may download and print one copy of any publication from the public portal for the purpose of private study or research.

- You may not further distribute the material or use it for any profit-making activity or commercial gain

- You may freely distribute the URL identifying the publication in the public portal

If you believe that this document breaches copyright please contact us providing details, and we will remove access to the work immediately and investigate your claim 
Session $4 a 5$

\title{
Integration of Basic Electromagnetism and Engineering Technology
}

\author{
Sigurd Bentz \\ Technical University of Denrnark
}

\begin{abstract}
The theory of electromagnetism is taught as a part of most contemporary electrical engineering curricula. Usually a basic course is intended to cover all the fundamental electromagnetic theory which is needed in later engineering courses. However, it is often found that students fail to understand and retain much of the course material, which in turn makes their subsequent studies more difficult.

In this paper we describe a freshman course in electromagnetism which alleviates these problems. Our hypothesis is that the course material is difficult to grasp because of its abstract nature. Consequently, the purely theoretical course contents have been reduced to a core of fundamental principles. These are combined with the study of magnetic properties of materials closely related to manufacturer's data sheets. To enhance the understanding of these fundamentals, practical topics from engineering technology are included. Components or systems that combine magnetic, electrical and mechanical aspects are preferred. Also, a series of hands-on lab projects give the students an opportunity to learn by doing.

The topics that are covered by the course are outlined. By integrating the teaching of basic physical laws and their application in technology students get a more comprehensive understanding of electromagnetism, and they are able to apply the physical principles to problems they encounter later in their careers.
\end{abstract}

\section{Background}

The setting for this work is an undergraduate school of electrical and electronic engineering $(\mathrm{EE})$. While we have no background for drawing conclusions for other parts of engineering education, we believe that the principles presented here can be applied in other settings as well.

Electromagnetism (EM) is fundamental for most of the broad range of electrical and electronic engineering. EM is thus an obvious part of an EE programme, but a trend over the last 30 years has been that pressure from new topics has decreased the weight of EM in a curriculum. Nevertheless, everybody seems to be convinced, that EM will remain in EE programs [1][2].

The teaching of EM is traditionally covered by a basic course and one or more engineering courses. The basic course is often taught by the department of science. Our current textbook has the title:

\section{Physics for Scientists and Engineers [3]}

As the title suggests, there is equal concern for scientists and engineers. Further, there is a concern for engineering students from different programs. This broad scope of a textbook indicates that maybe, it isn't good for anybody.

The engineering courses are taught by the engineering department. They might have topics such as EM field propagation, energy converting devices, or sensors and actuators. There seems to be a low interaction between the basic course and the engineering courses, where hardly any prerequisites are expected from the basic course. The faculty teaching the two types of courses seem to communicate very little.

The engineering curriculum is aiways overloaded. New technologies need to be included. Fading technologies are hard to skip. In a period with a decreasing number of class hours it is obvious, that also EM courses have a limited time to cover their material.

Students consider EM to be difficult. With fewer applicants, and with a less engineering oriented high school education, it is obvious, that these complaints will grow. $\mathrm{EM}$ is as difficult as physics in general. Students need to have a certain level of understanding, before EM can be of any good to them. A mere training in solving typical examination problems will help the students to pass their exams, but not to get any benefit from what they were supposed to learn. We think it is an experience for every teacher in $\mathrm{EE}$, that the retention level for EM is indeed very, very low for the majority of students.

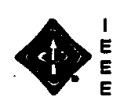




\section{The Concept of Integration}

A model for integration of basic EM and engineering technology within a single course can be described in the following three steps.

The first step is to reduce the amount of traditional EM theory to-say-approximately $40 \%$ of the available time. This is a severe cut. It requires, that every single topic be assessed carefully. Only topics which are necessary for the course itself, which are prerequisites for the EE education as a whole, or which are supposed to be part of an electrical engineer's general background will survive as part of the fundamental core of the curriculum. Many physical principles are beautiful illustrations of the physical laws, but that is not reason enough to retain them.

The second step is to recognize the importance of material science for technological development today. Most elementary textbooks give only a superficial overview of material properties. In contrast, many applications depend heavily on specific material properties-possibly even in interaction with the mode of operation. Material science on an engineering basis should be included for 10 to $20 \%$ of the available time.

The third step is to introduce engineering technology based on physical laws, as well as material properties, for approximately $40 \%$ of the available time. In fact, we see this as an expression of the most genuine engineering activity. So far as possible, this part of the curriculum should be spread all over the semester. The technological part of the course has three objectives: It legitimates the study of EM in EE. It demonstrates the relevance of EM for the engineering profession as well as for the every day life. It enhances greatly the student's understanding and retention of the course material.

\section{Case Study: A Freshman Course of Magnetism}

The objective of this course is to give the students a thorough understanding of the magnetic field and enable them to design simple magnetic systems.

\section{EM Theory}

We have identified four basics of magnetism, which are the necessary theoretical core of the course. Moreover, they have almost no value one at a time, but should be seen as a totality.

Ampère's law explains that every current creates a magnetic field. In certain cases we can even calculate the magnetic field with Ampère's law. This law links the electrical (current/voltage) domain with the magnetic domain.
Alternative sources of magnetic fields are permanent magnetic materials. They are handled in a different way.

Gauss' law explains that magnetic induction lines have no beginning and no end. Further it gives the background for keeping account of the magnetic flux.

Material properties are expressed as a relation between magnetic induction $B$ and magnetic field strength $H$. This relation can either be analytic or graphical.

Faraday's law, or the law of induction, expresses that any time-variation of magnetic flux will induce an electromotive force. This law is the second link between the electric and the magnetic domain.

Beside these four fundamentals a link between the mechanical and the magnetic domain is needed. Therefore different expressions for the force of the magnetic field are included.

Other useful relations like the boundary conditions are omitted.

\section{Material Science}

Material properties have both a scientific and a practical expression. In an engineering course the practical way should be chosen. Guidelines for this can be found in manufacturer's data sheets, in textbooks on materials, or by considering the data that can be measured in an ordinary electronics development lab.

We see it as an objective, that the students after the course are able to read, understand and apply technical information for materials and components in a professional manner. One reason is, that the students will realise, that they have accomplished, during the course, something which is useful for their careers. Another reason is that this will be a link to the real world outside the ivory tower of the university.

\section{Engineering Technology}

We have identified areas of technology which might be useful as 'suppliers' of case studies for the magnetism course. The applications are selected by virtue of their relevance for $\mathrm{EE}$ and their impact on society:

- Magnetic field hazards to the human body.

- Measurement of magnetic fields.

- Magnetic field emission, e.g. HV overhead transmission lines, video display units, household equipment.

- Susceptibility of electronic equipment to magnetic fields.

- Electromagnetic interference, electromagnetic compatibility.

- Magnetic components, e.g. Hall generators, inductors, transformers, magnetic circuits.

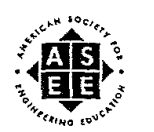

1995 Frontiers in Education Conference $4 a 5.5$

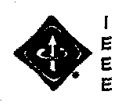


- Sensors, actuators, transducers.

- Oersted, the first Danish satellite. It will be launched in 1996 in order to measure the geomagnetic field.

Systems combining magnetic, electrical and mechanical aspects are preferred, because they link important parts of the EE curriculum.

For the spring semester 1995 we have chosen to give an in-depth discussion of the following components in the lectures:

Hall generator
Helmholtz coils
Galvanometer
Filter inductor
Inductor with air gap
Small transformer for power supplies
Loudspeaker magnet systems
Dynamic behaviour of an electrodynamic loudspeaker

It is a principle to include practical aspects wherever possible. To mention a few examples: We don't stop by calculating inductance for a solenoid-we emphasize the parasitic inductance of every current loop. When we calculate the magnetic field from a straight wire or a circular loop, we also show what the fields look like around a HV overhead transmission line or a microwave oven.

The choice of examples can change, but the course content is fundamentally the same.

\section{Laboratory Projects}

The integrated course gives a sound basis for, and is enhanced by, a series of student hands-on laboratory projects. We have changed from four one-afternoon 'cook book' laboratory experiments to one student project running over the full length of a semester.

The students work in groups of three and they can choose their project from a list of proposals. Student proposals are accepted if possible. During the semester the group works on an open-ended project. At the end of the semester the students present their work in written as well as oral form.

The actual projects in the spring semester 1995 were:

Helmholtz coils

RFI filter chokes

Simulation of nonlinear inductors (including hysteresis) with PSpice

Loudspeakers

DC field measurements with Hall generator

$50 \mathrm{c} / \mathrm{s}$ field measurements with an one-axial pickup coil

IEC 1000-4-8 Power frequency magnetic immunity tests Pulse wire sensors

\section{Evaluation}

The course is evaluated by the students with an anonymous questionnaire. Of the nine questions the following are relevant to our topic:

- Do you find the course content presented in an understanclable form?

- Is there a reasonable balance between theory and examples/problems?

- Are you actively participating in the teaching/learning?

- Do you give this course a high priority when you plan your time schedule?

The answers on these questions can best be presented by comparing their 'mean value' with the 'mean value' of all students, all teachers and all courses in the department. The evaluation over three semesters has shown, that the magnetisin course now is well above the over-all score.

A further evaluation is to be found in the lab reports. This is, of course, more subjective. The general impression (of the teachers) until now is, that the students are more motivated, they ask more questions about their findings and they work harder and more on their own. While the students only have handled one topic during their laboratory work, we find that they have got more understanding of magnetic issues in general than before.

An important by-product is the gained experience of working as a project group.

\section{Conclusions}

By applying physical laws on components and systems relevant to electrical engineers and to daily life and by giving more attention to material properties, it has been shown that students are more motivated for the course, they work more cornmitted and they get a more comprehensive understanding of electromagnetism. So far we feel confident, that they also will be able to apply the physical principles later in their careers. A drawback is that no textbooks are available

At the undergraduate school of the Technical University of Denmark the concept of integration has been appreciated for years. The ongoing reengineering of this subject area has led to a confirmation of the sound basis of this concept.

\section{References}

[1] Angelakos, D. J. University of Califomia at Berkeley; Kino, G. S. Stanford University; Pantic-Tanner, Z. and Trauner, R. San Francisco State University. Private communications.

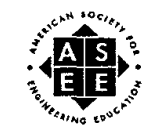
1995 Frontiers in Education Conference 4 a5.6

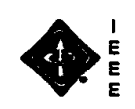


[2] Van Valkenburg, M. E. An Engineering Curriculum for the Future. IEEE Communications Magazine, Vol. 28, No. 12, December 1990.

[3] Fishbane,P. M; Gasiorowicz, S. and Thomton, S. T. Physics for Scientists and Engineers, Extended Version. PrenticeHall 1993. 